Article

\title{
Novel 1,3,4-Oxadiazole Derivatives Containing a Cinnamic Acid Moiety as Potential Bactericide for Rice Bacterial Diseases
}

\author{
Shaobo Wang, Xiuhai Gan *D, Yanju Wang, Shaoyuan Li, Chongfen Yi, Jixiang Chen, \\ Fangcheng He, Yuyuan Yang, Deyu Hu and Baoan Song * (D)
}

State Key Laboratory Breeding Base of Green Pesticide and Agricultural Bioengineering/Key Laboratory of Green Pesticide and Agricultural Bioengineering, Ministry of Education, Guizhou University, Huaxi District, Guiyang 550025, China; wangshaobo97@126.com (S.W.); 18985900557@163.com (Y.W.); 15761626670@163.com (S.L.); 13608581558@163.com (C.Y.); 18230826028@163.com (J.C.); 13667177168@163.com (F.H.); gs.yuyuanyang17@gzu.edu.cn (Y.Y.); dyhu@gzu.edu.cn (D.H.)

* Correspondence: gxh200719@163.com (X.G.); songbaoan22@yahoo.com (B.S.); Tel.: +86(851)88362-0521 (B.S.)

Received: 4 February 2019; Accepted: 21 February 2019; Published: 26 February 2019

\begin{abstract}
Rice bacterial leaf blight and leaf streak are two important bacterial diseases of rice, which can result in yield loss. Currently, effective antimicrobials for rice bacterial diseases are still lacking. Thus, to develop highly effective and low-risk bactericides, 31 novel 1,3,4-oxadiazole derivatives containing a cinnamic acid moiety were designed and synthesized. Bioassay results demonstrated that all compounds exhibited good antibacterial activities in vitro. Significantly, compounds 5r and $5 \mathbf{t}$ showed excellent antibacterial activities against Xanthomonas oryzae pv. oryzae (Xoo) and $X$. oryzae pv. oryzicola $(X o c)$, with the $50 \%$ effective concentration $\left(\mathrm{EC}_{50}\right)$ values of 0.58 and 0.34 , and 0.44 and $0.20 \mu \mathrm{g} / \mathrm{mL}$, respectively. These compounds were much better than thiodiazole copper (123.10 and $161.52 \mu \mathrm{g} / \mathrm{mL}$ ) and bismerthiazol (85.66 and $110.96 \mu \mathrm{g} / \mathrm{mL}$ ). Moreover, compound 5t had better protective and curative activities against rice bacterial leaf blight and leaf streak than thiodiazole copper and bismerthiazol in vivo. Simultaneously, the in vivo efficacy of the compounds was demonstrated by real-time quantitative PCR to quantify bacterial titers. In addition, a three-dimensional quantitative structure-activity relationship model was created and presented good predictive ability. This work provides support for 1,3,4-oxadiazole derivatives containing a cinnamic acid moiety as a potential new bactericide for rice bacterial diseases.
\end{abstract}

Keywords: 1,3,4-oxadiazole derivatives; cinnamic acid; bacterial diseases; antibacterial activity; 3D-QSAR; real-time quantitative PCR

\section{Introduction}

As the main food crop for more than half of the world's population, rice is susceptible to a large number of pathogenic microorganisms, which can cause devastating diseases and result in serious loss of production worldwide, threatening global food security [1-3]. In rice-growing countries, rice bacterial leaf blight and leaf streak are two important devastating bacterial diseases of rice; they are caused by the pathogens Xanthomonas oryzae pv. oryzae (Xoo) and X. oryzae pv. oryzicola (Xoc), respectively $[4,5]$. These two kinds of bacterial diseases can occur either individually or collectively, and over the past 30 years, each of them has been shown to result in yield loss of at least $10 \%$ of susceptible rice varieties grown on a large scale [4]. The hazards are increasing with the annual expansion of planting areas. Currently, few bactericides, such as bismerthiazol, thiodiazole copper, zinc thiazole, and zhongshengmycin are available for controlling rice bacterial diseases. However, rice bacterial leaf blight and leaf streak have not yet been effectively controlled, and the intensive and 
continuous use of the same bactericide has led to the development of drug-resistant pathogens in the bacterial population [6-8]. Therefore, developing new, highly effective bactericides for controlling the two bacterial diseases of rice is an imperative and daunting task.

Over the past few decades, natural products have been used in the development of new pesticides, given their advantages of easy decomposition and environmental friendliness. As one of the natural aromatic fatty acids, cinnamic acid is the deaminated product of phenylalanine in plant tissues [9]. Substituted cinnamic acids show diverse biological activities, such as antitumor [9], antioxidation [10,11], insecticidal [12], antiviral [13,14], fungicidal [15,16], bactericidal [17], and herbicidal activities [18], and have attracted the attention of many researchers. In particular, many cinnamic acid analogs are crucial and promising compounds as potential antifungal and antibacterial agents [19]. Reportedly, cinnamic acid has been shown to have an excellent bactericidal effect in combination with fumaric acid [20].

1,3,4-Oxadiazole derivatives are an important class of nitrogen-containing heterocyclic compounds and are used as pesticides because of their antibacterial [21-23], antifungal [24], nematicidal [25], antiviral [26], herbicidal [27], and insecticidal activities [28]. In our previous works, we found that some novel 1,3,4-oxadiazole derivatives containing the sulfone moiety showed potent antibacterial and antifungal activities [21-24]. Among them, compounds $\mathbf{a}$ and $\mathbf{b}$ displayed excellent activities for controlling rice bacterial leaf blight and leaf streak diseases, as shown in Figure 1. The relationship between the structure and activity confirmed that the 1,3,4-oxadiazole-sulfone backbone is a vital pharmacophore.
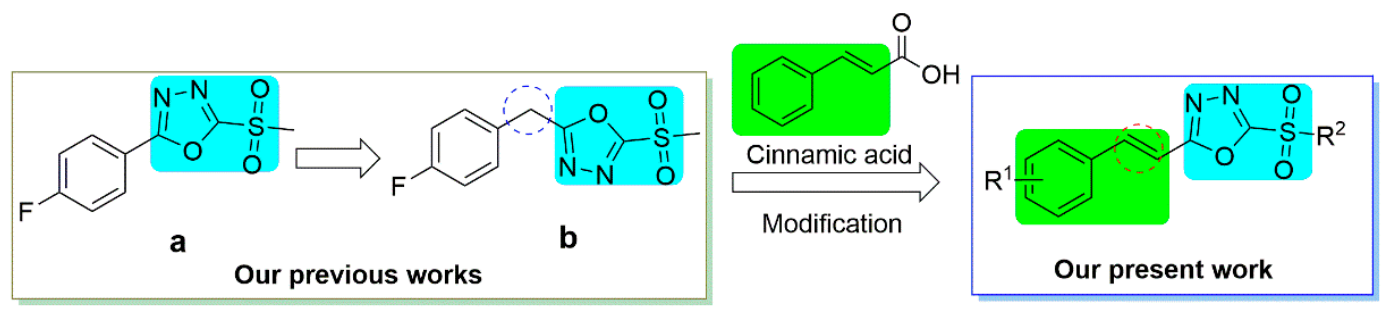

Figure 1. Design of the target compounds.

To continue the research on 1,3,4-oxadiazole derivatives, we set out to create novel 1,3,4-oxadiazole derivatives containing a cinnamic acid moiety replacing the methylene group with a vinyl group in the present work, as shown in Figure 1. In addition, we tested their antibacterial activities for rice bacterial leaf blight and leaf streak in vitro and in vivo. Moreover, the in vivo efficacy of the compounds was confirmed by real-time quantitative PCR assays. We also established a three-dimensional quantitative structure-activity relationship (3D-QSAR) model.

\section{Results}

\subsection{Synthesis}

The pathways for the synthesis of the 1,3,4-oxadiazole derivatives containing a cinnamic acid moiety are described and shown in Scheme 1 . The different substituted cinnamic acids were used as the starting materials via hydrazidation, cyclization, thioetherification, and oxidation reaction to obtain the target compounds. 

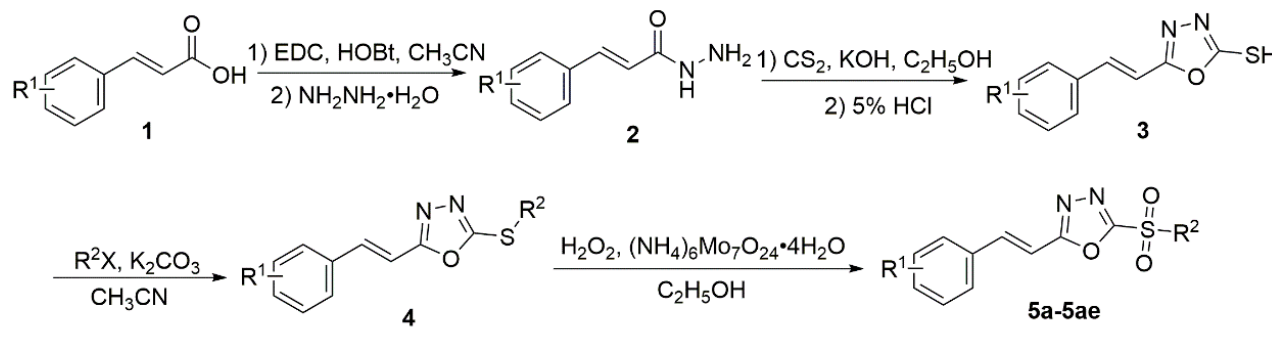

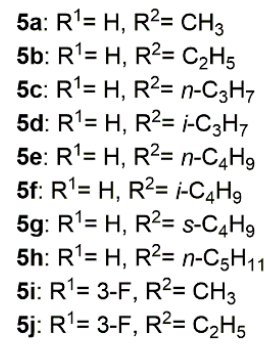

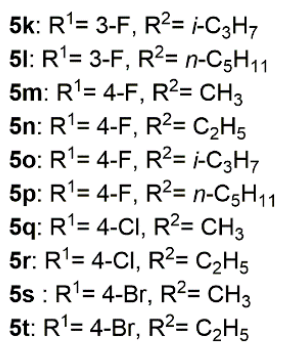

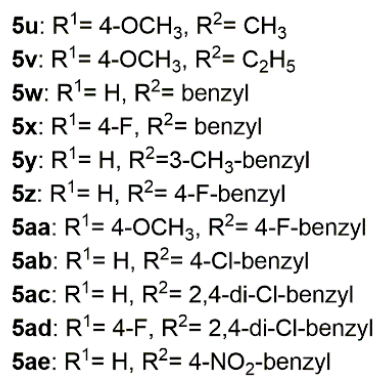

Scheme 1. Synthesis of the target compounds 5a-5ae.

\subsection{In Vitro Antibacterial Activity}

\subsubsection{In Vitro Antibacterial Activity of Xoo}

The title compounds 5a-5ae were tested for in vitro antibacterial activities against rice bacterial leaf blight caused by Xoo via the turbidimeter test. The results are shown in Table 1.

Table 1. Antibacterial activity of the target compounds against Xoo in vitro.

\begin{tabular}{|c|c|c|c|c|c|}
\hline \multirow{2}{*}{ Compound } & \multicolumn{2}{|c|}{ Inhibition $(\%)$} & \multirow{2}{*}{$\begin{array}{c}\text { Toxic Regression } \\
\text { Equation }\end{array}$} & \multirow{2}{*}{$r$} & \multirow{2}{*}{$\mathrm{EC}_{50}(\mu \mathrm{g} / \mathrm{mL})^{a}$} \\
\hline & $50(\mu \mathrm{g} / \mathrm{mL})$ & $5(\mu \mathrm{g} / \mathrm{mL})$ & & & \\
\hline $5 \mathbf{a}$ & 100 & $57.1 \pm 3.3$ & $y=1.70 x+4.08$ & 0.99 & $3.47 \pm 1.47$ \\
\hline $5 b$ & 100 & $77.2 \pm 1.0$ & $y=4.84 x+2.40$ & 0.96 & $3.43 \pm 0.77$ \\
\hline $5 c$ & $97.7 \pm 2.2$ & $48.6 \pm 1.8$ & $y=1.82 x+4.42$ & 0.98 & $2.08 \pm 1.13$ \\
\hline $5 d$ & 100 & $77.1 \pm 1.4$ & $y=1.39 x+4.91$ & 0.99 & $1.15 \pm 0.93$ \\
\hline $5 e$ & $74.1 \pm 1.0$ & $71.3 \pm 2.4$ & $y=1.44 x+4.64$ & 0.99 & $1.76 \pm 0.80$ \\
\hline $5 f$ & $92.2 \pm 1.5$ & $65.3 \pm 0.9$ & $y=1.06 x+4.40$ & 0.96 & $3.60 \pm 1.13$ \\
\hline $5 g$ & $93.1 \pm 3.3$ & $49.9 \pm 2.5$ & $y=1.54 x+3.91$ & 0.96 & $5.06 \pm 1.71$ \\
\hline $5 \mathrm{~h}$ & $99.1 \pm 1.0$ & $65.3 \pm 4.9$ & $y=1.67 x+3.48$ & 0.96 & $8.07 \pm 2.66$ \\
\hline $5 \mathbf{i}$ & $91.8 \pm 3.0$ & $79.6 \pm 1.6$ & $y=1.51 x+4.63$ & 0.97 & $1.75 \pm 0.97$ \\
\hline $5 \mathbf{j}$ & $97.2 \pm 4.0$ & $72.4 \pm 4.9$ & $y=1.56 x+4.41$ & 0.99 & $2.38 \pm 1.17$ \\
\hline $5 k$ & 100 & $82.8 \pm 3.1$ & $y=1.30 x+5.28$ & 0.97 & $0.61 \pm 0.43$ \\
\hline 51 & $89.8 \pm 1.9$ & $37.3 \pm 2.5$ & $y=0.87 x+4.06$ & 0.99 & $11.83 \pm 3.43$ \\
\hline $5 \mathrm{~m}$ & $97.6 \pm 1.8$ & $92.5 \pm 1.4$ & $y=4.56 x+3.37$ & 0.97 & $2.28 \pm 0.41$ \\
\hline $5 n$ & 100 & $77.2 \pm 3.3$ & $y=1.49 x+4.67$ & 0.91 & $1.67 \pm 0.65$ \\
\hline 50 & $95.2 \pm 4.3$ & $88.1 \pm 4.1$ & $y=1.06 x+4.94$ & 0.96 & $1.42 \pm 0.70$ \\
\hline $5 p$ & $88.0 \pm 2.6$ & $63.3 \pm 3.4$ & $y=0.79 x+4.85$ & 0.97 & $1.53 \pm 1.18$ \\
\hline $5 q$ & 100 & 100 & $y=3.68 x+5.51$ & 0.91 & $0.72 \pm 0.22$ \\
\hline $5 r$ & 100 & $97.3 \pm 0.8$ & $y=2.33 x+5.55$ & 0.99 & $0.58 \pm 0.35$ \\
\hline $5 s$ & 100 & $76.0 \pm 4.8$ & $y=2.92 x+5.03$ & 0.90 & $0.97 \pm 0.41$ \\
\hline $5 t$ & 100 & $99.8 \pm 0.2$ & $y=1.97 x+5.70$ & 0.96 & $0.44 \pm 0.26$ \\
\hline $5 \mathbf{u}$ & $93.8 \pm 4.0$ & $57.9 \pm 3.2$ & $y=2.80 x+3.81$ & 0.99 & $2.66 \pm 0.92$ \\
\hline $5 v$ & $96.7 \pm 2.3$ & $67.3 \pm 1.0$ & $y=1.89 x+4.46$ & 0.95 & $1.93 \pm 0.85$ \\
\hline $5 w$ & 100 & $55.9 \pm 1.0$ & $y=2.20 x+2.00$ & 0.93 & $22.74 \pm 3.62$ \\
\hline $5 x$ & $82.2 \pm 4.1$ & $65.4 \pm 3.0$ & $y=1.22 x+4.27$ & 0.94 & $3.95 \pm 1.11$ \\
\hline $5 y$ & 100 & $54.0 \pm 2.7$ & $y=1.43 x+3.12$ & 0.91 & $20.95 \pm 4.32$ \\
\hline $5 z$ & $63.3 \pm 5.0$ & $32.5 \pm 3.7$ & $y=1.24 x+3.38$ & 0.98 & $19.90 \pm 4.84$ \\
\hline $5 \mathbf{a a}$ & $82.6 \pm 1.3$ & $44.3 \pm 1.5$ & $y=1.00 x+3.80$ & 0.97 & $15.94 \pm 3.03$ \\
\hline $5 \mathrm{ab}$ & $67.9 \pm 4.3$ & $37.9 \pm 2.7$ & $y=0.80 x+3.98$ & 0.99 & $19.34 \pm 3.24$ \\
\hline
\end{tabular}

a Average of three replicates. 
Table 1. Cop.

\begin{tabular}{cccccc}
\hline \multirow{2}{*}{ Compound } & \multicolumn{2}{c}{ Inhibition (\%) } & Toxic Regression & $\boldsymbol{r}$ & $\mathbf{E C}_{\mathbf{5 0}}(\boldsymbol{\mu g} / \mathbf{m L})^{\mathbf{a}}$ \\
\cline { 2 - 4 } & $\mathbf{5 0}(\boldsymbol{\mu} \mathbf{g} \mathbf{m L})$ & $\mathbf{5}(\boldsymbol{\mu g} / \mathbf{m L})$ & Equation & & \\
\hline 5 ac & $90.1 \pm 1.3$ & $50.5 \pm 2.3$ & $y=0.63 \mathrm{x}+4.60$ & 0.98 & $4.43 \pm 1.74$ \\
$\mathbf{5 a d}$ & $95.2 \pm 2.0$ & $58.7 \pm 3.1$ & $\mathrm{y}=0.62 \mathrm{x}+4.92$ & 0.97 & $1.36 \pm 0.69$ \\
$\mathbf{5 a e}$ & 100 & $59.3 \pm 0.3$ & $\mathrm{y}=0.60 \mathrm{x}+4.10$ & 0.96 & $4.00 \pm 2.73$ \\
Cinnamic acid & $10.3 \pm 4.3$ & $1.4 \pm 0.5$ & $\mathrm{y}=4.57 \mathrm{x}-5.85$ & 0.98 & $236.07 \pm 6.29$ \\
$\mathbf{a}$ & 100 & $90.1 \pm 3.7$ & $\mathrm{y}=2.65 \mathrm{x}+4.85$ & 0.97 & $1.41 \pm 0.64$ \\
$\mathbf{b}$ & 100 & $84.8 \pm 2.9$ & $\mathrm{y}=6.78 \mathrm{x}+5.50$ & 0.97 & $0.84 \pm 0.33$ \\
Bismerthiazol & $38.9 \pm 1.8$ & $4.2 \pm 1.4$ & $\mathrm{y}=2.35 \mathrm{x}+0.53$ & 0.95 & $85.66 \pm 4.10$ \\
Thiodiazole copper & $34.3 \pm 2.6$ & $1.9 \pm 0.5$ & $\mathrm{y}=1.67 \mathrm{x}+1.49$ & 0.95 & $123.10 \pm 4.74$ \\
\hline \multicolumn{5}{c}{ a Average of three replicates. }
\end{tabular}

As shown in Table 1, all the title compounds showed better bactericidal activities against Xoo than the commercial agents bismerthiazol and thiodiazole copper. Among them, compounds $\mathbf{5 a}, \mathbf{5 b}, \mathbf{5 d}, \mathbf{5 k}$, $\mathbf{5 n}, \mathbf{5 q}, \mathbf{5 r}, \mathbf{5 s}, \mathbf{5 t}, \mathbf{5 w}, \mathbf{5 y}$, and $\mathbf{5 a e}$ showed good antibacterial activities with inhibition rates of $100 \%$ at $50 \mu \mathrm{g} / \mathrm{mL}$ concentration. The compounds $\mathbf{5 q}, \mathbf{5 r}$, and $\mathbf{5 t}$ showed excellent antibacterial activities with inhibition rates of $100 \%, 97.3 \%$, and $99.8 \%$, respectively, at $5 \mu \mathrm{g} / \mathrm{mL}$ concentration. In addition, the $50 \%$ effective concentration $\left(\mathrm{EC}_{50}\right)$ values of the target compounds $\mathbf{5 a - 5 a e}$ were tested. As shown in Table 1, all the target compounds showed better antibacterial activity than thiodiazole copper $(123.10 \mu \mathrm{g} / \mathrm{mL})$, bismerthiazol $(85.66 \mu \mathrm{g} / \mathrm{mL})$, and cinnamic acid $(236.07 \mu \mathrm{g} / \mathrm{mL})$. Compounds $5 \mathbf{r}$ and $5 t$ showed the most obvious antibacterial activity with $\mathrm{EC}_{50}$ values of 0.58 and $0.44 \mu \mathrm{g} / \mathrm{mL}$, respectively, which were higher than those of leading compounds $\mathbf{a}(1.41 \mu \mathrm{g} / \mathrm{mL})$ and $\mathbf{b}(0.84 \mu \mathrm{g} / \mathrm{mL})$.

\subsubsection{In Vitro Antibacterial Activity of Xoc}

The in vitro antibacterial activities of the title compounds 5a-5ae against Xoc were evaluated using the turbidimeter test. As shown in Table 2, all the target compounds revealed better bactericidal activities against Xoc than bismerthiazol and thiodiazole copper. Among them, compounds $5 \mathbf{k}, 5 \mathrm{~m}$, $\mathbf{5 n}, \mathbf{5 q}, \mathbf{5 r}, \mathbf{5 s}$, and $\mathbf{5 t}$ had good antibacterial activity with inhibition rates of $100 \%$ at $50 \mu \mathrm{g} / \mathrm{mL}$ concentration. Compounds $\mathbf{5 k}, \mathbf{5} \mathbf{r}$, and $\mathbf{5 t}$ showed excellent antibacterial activity with inhibition rates of $92.5 \%, 96.6 \%$, and $98.2 \%$ at $5 \mu \mathrm{g} / \mathrm{mL}$, respectively. Furthermore, the $\mathrm{EC}_{50}$ values of the target compounds 5a-5ae were tested, and all of them showed better antibacterial activity against Xoc than thiodiazole copper $(161.52 \mu \mathrm{g} / \mathrm{mL})$ and bismerthiazol $(110.96 \mu \mathrm{g} / \mathrm{mL})$. Compounds $5 \mathbf{r}$ and $\mathbf{5 t}$ showed excellent antibacterial activity with $\mathrm{EC}_{50}$ values of 0.34 and $0.20 \mu \mathrm{g} / \mathrm{mL}$, respectively, which were higher than those of compounds $\mathbf{a}(2.01 \mu \mathrm{g} / \mathrm{mL})$ and $\mathbf{b}(1.16 \mu \mathrm{g} / \mathrm{mL})$.

Table 2. Antibacterial activity of the target compounds against Xoc in vitro.

\begin{tabular}{|c|c|c|c|c|c|}
\hline \multirow{2}{*}{ Compound } & \multicolumn{2}{|c|}{ Inhibition (\%) } & \multirow{2}{*}{$\begin{array}{c}\text { Toxic Regression } \\
\text { Equation }\end{array}$} & \multirow{2}{*}{$r$} & \multirow{2}{*}{$\mathrm{EC}_{50}(\mu \mathrm{g} / \mathrm{mL})^{a}$} \\
\hline & $50(\mu \mathrm{g} / \mathrm{mL})$ & $5(\mu \mathrm{g} / \mathrm{mL})$ & & & \\
\hline $5 a$ & $98.1 \pm 1.5$ & $58.5 \pm 1.9$ & $y=1.20 x+4.50$ & 0.98 & $2.65 \pm 1.87$ \\
\hline $5 b$ & $91.3 \pm 2.2$ & $39.1 \pm 1.2$ & $y=1.62 x+3.69$ & 0.98 & $6.42 \pm 1.93$ \\
\hline $5 c$ & $97.6 \pm 2.7$ & $38.5 \pm 3.0$ & $y=1.90 x+3.48$ & 0.99 & $6.27 \pm 2.79$ \\
\hline $5 d$ & $97.9 \pm 2.5$ & $31.3 \pm 4.4$ & $y=2.33 x+3.33$ & 0.96 & $5.23 \pm 3.96$ \\
\hline $5 e$ & $74.8 \pm 4.7$ & $11.0 \pm 3.9$ & $y=3.63 x+0.27$ & 0.93 & $19.86 \pm 3.26$ \\
\hline $5 f$ & $90.4 \pm 1.3$ & $47.8 \pm 1.8$ & $y=1.31 x+4.08$ & 0.97 & $4.94 \pm 1.81$ \\
\hline $5 g$ & $89.3 \pm 2.2$ & $64.4 \pm 1.4$ & $y=1.03 x+4.49$ & 0.97 & $3.06 \pm 1.87$ \\
\hline $5 \mathrm{~h}$ & $46.9 \pm 2.3$ & $7.7 \pm 0.9$ & $y=1.79 x+2.20$ & 0.96 & $36.44 \pm 2.90$ \\
\hline $5 i$ & $97.9 \pm 1.8$ & $34.4 \pm 4.5$ & $y=2.15 x+4.65$ & 0.95 & $1.45 \pm 1.77$ \\
\hline $5 \mathbf{j}$ & $98.6 \pm 1.1$ & $69.5 \pm 4.3$ & $y=1.35 x+4.75$ & 0.99 & $1.51 \pm 1.18$ \\
\hline $5 \mathbf{k}$ & 100 & $92.5 \pm 2.5$ & $y=3.04 x+4.26$ & 0.94 & $1.76 \pm 0.74$ \\
\hline 51 & $90.7 \pm 3.8$ & $69.0 \pm 4.4$ & $y=0.82 x+4.95$ & 0.99 & $1.16 \pm 0.93$ \\
\hline $5 \mathrm{~m}$ & 100 & $83.0 \pm 2.8$ & $y=1.49 x+4.89$ & 0.98 & $1.17 \pm 0.60$ \\
\hline
\end{tabular}


Table 2. Cont

\begin{tabular}{|c|c|c|c|c|c|}
\hline \multirow{2}{*}{ Compound } & \multicolumn{2}{|c|}{ Inhibition (\%) } & \multirow{2}{*}{$\begin{array}{l}\text { Toxic Regression } \\
\text { Equation }\end{array}$} & \multirow{2}{*}{$r$} & \multirow{2}{*}{$\mathrm{EC}_{50}(\mu \mathrm{g} / \mathrm{mL})^{\mathrm{a}}$} \\
\hline & $50(\mu \mathrm{g} / \mathrm{mL})$ & $5(\mu \mathrm{g} / \mathrm{mL})$ & & & \\
\hline $5 n$ & 100 & $77.4 \pm 1.3$ & $y=1.49 x+4.67$ & 0.91 & $1.49 \pm 0.93$ \\
\hline 50 & $75.7 \pm 4.2$ & $46.5 \pm 3.3$ & $y=0.78 x+4.35$ & 0.97 & $6.71 \pm 3.23$ \\
\hline $5 p$ & $67.7 \pm 3.8$ & $50.9 \pm 0.8$ & $y=0.41 x+4.73$ & 0.91 & $4.24 \pm 2.02$ \\
\hline $5 q$ & 100 & $72.8 \pm 1.8$ & $y=0.79 x+5.00$ & 0.93 & $0.97 \pm 0.49$ \\
\hline $5 r$ & 100 & $96.6 \pm 1.3$ & $y=2.33 x+6.09$ & 0.99 & $0.34 \pm 0.20$ \\
\hline $5 s$ & 100 & $83.7 \pm 0.8$ & $y=0.67 x+5.05$ & 0.97 & $0.82 \pm 0.32$ \\
\hline $5 t$ & 100 & $98.2 \pm 2.0$ & $y=2.09 x+6.47$ & 0.98 & $0.20 \pm 0.13$ \\
\hline $5 \mathbf{u}$ & $94.4 \pm 4.7$ & $77.6 \pm 1.0$ & $y=0.62 x+5.26$ & 0.98 & $0.38 \pm 0.14$ \\
\hline $5 v$ & $77.1 \pm 2.8$ & $64.8 \pm 2.3$ & $y=0.46 x+4.97$ & 0.93 & $1.14 \pm 0.66$ \\
\hline $5 w$ & $66.9 \pm 4.4$ & $32.4 \pm 2.2$ & $y=0.97 x+3.81$ & 0.98 & $16.44 \pm 2.98$ \\
\hline $5 x$ & $91.7 \pm 4.9$ & $59.2 \pm 1.3$ & $y=1.16 x+4.26$ & 0.97 & $2.82 \pm 1.51$ \\
\hline $5 y$ & $83.5 \pm 3.1$ & $58.6 \pm 3.1$ & $y=0.66 x+4.61$ & 0.94 & $3.87 \pm 2.33$ \\
\hline $5 z$ & $67.0 \pm 2.6$ & $36.2 \pm 3.7$ & $y=0.72 x+4.13$ & 0.96 & $16.37 \pm 3.72$ \\
\hline 5 aa & $77.1 \pm 2.6$ & $44.7 \pm 2.5$ & $y=1.11 x+3.91$ & 0.97 & $9.57 \pm 4.36$ \\
\hline $5 \mathrm{ab}$ & $70.4 \pm 0.8$ & $40.9 \pm 2.8$ & $y=0.82 x+4.11$ & 0.98 & $12.20 \pm 2.03$ \\
\hline $5 \mathrm{ac}$ & $74.3 \pm 1.1$ & $41.4 \pm 2.3$ & $y=0.71 x+4.25$ & 0.99 & $11.54 \pm 3.44$ \\
\hline $5 \mathrm{ad}$ & $99.0 \pm 1.0$ & $78.2 \pm 4.8$ & $y=1.94 x+4.16$ & 0.97 & $2.69 \pm 1.10$ \\
\hline 5 ae & $78.3 \pm 2.5$ & $54.8 \pm 3.2$ & $y=0.80 x+4.55$ & 0.95 & $3.52 \pm 1.25$ \\
\hline Cinnamic acid & $16.9 \pm 3.0$ & $2.2 \pm 1.2$ & $y=1.07 x+1.89$ & 0.96 & $270.45 \pm 6.51$ \\
\hline a & 100 & $98.1 \pm 0.9$ & $y=3.67 x+3.88$ & 0.98 & $2.01 \pm 0.76$ \\
\hline $\mathbf{b}$ & 100 & $93.0 \pm 2.2$ & $y=1.63 x+4.89$ & 0.96 & $1.16 \pm 0.57$ \\
\hline Bismerthiazol & $24.4 \pm 4.0$ & $2.6 \pm 1.8$ & $y=2.04 x+0.81$ & 0.97 & $110.96 \pm 2.79$ \\
\hline Thiodiazole copper & $18.7 \pm 3.2$ & $1.6 \pm 0.6$ & $y=1.79 x+1.04$ & 0.95 & $161.52 \pm 4.84$ \\
\hline
\end{tabular}

\subsection{In Vivo Antibacterial Activity}

\subsubsection{In Vivo Antibacterial Activities Against Xoo}

As shown in Figure 2a and Table 3, at the concentration of $200 \mu \mathrm{g} / \mathrm{mL}$, the target compound $\mathbf{5 t}$ had good in vivo protective activities against rice bacterial leaf blight. The control efficiency was $66.62 \%$, which was superior to those of thiodiazole copper (57.33\%) and bismerthiazol (51.71\%). Figure $2 \mathrm{~b}$ and Table 4 reveal that compound $\mathbf{5 t}$ showed excellent in vivo curative activity against rice bacterial leaf blight with control efficiencies of $56.05 \%$, respectively, which was better than those of bismethylthiazole $(43.65 \%)$ and thiazole copper $(48.60 \%)$.

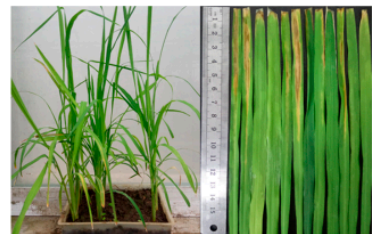

Thiodiazole copper

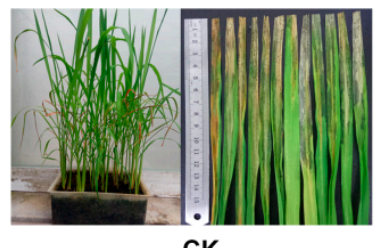

CK

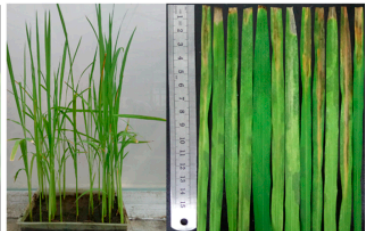

Bismerthiazol

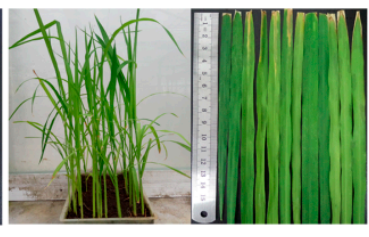

a

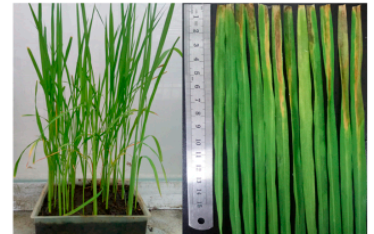

Thiodiazole copper

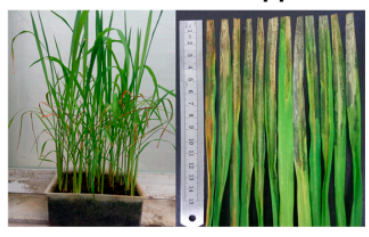

CK

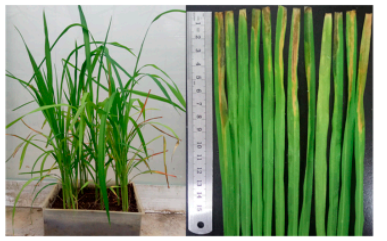

Bismerthiazol

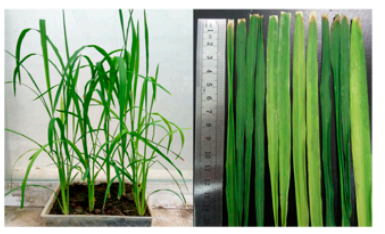

b
$5 t$

Figure 2. Protective (a) and curative (b) activities of compound $5 \mathbf{t}$ against rice bacterial leaf blight. 
Table 3. Protective activity of compound $5 \mathbf{t}$ against rice bacterial leaf blight.

\begin{tabular}{cccc}
\hline \multirow{2}{*}{ Treatment } & \multicolumn{3}{c}{ 14 Days after Spraying } \\
\cline { 2 - 4 } & Morbidity (\%) & Disease Index (\%) & Control Efficiency (\%) ${ }^{\mathbf{2}}$ \\
\hline 5t & 100 & 36.40 & $66.62 \pm 10.78^{\mathrm{a}}$ \\
Bismerthiazol & 100 & 46.89 & $51.71 \pm 6.90^{\mathrm{b}}$ \\
Thiodiazole copper & 100 & 44.50 & $57.33 \pm 7.26^{\mathrm{b}}$ \\
CK $^{1}$ & 100 & 86.70 & - \\
\hline
\end{tabular}

${ }^{1}$ Negative control (CK). ${ }^{2}$ Average of three replicates. Statistical analysis was performed by analysis of variance (ANOVA) in SPSS 17.0 software with equal variances assumed $(p>0.05)$ and equal variances not assumed $(p<0.05)$. The different lowercase letters indicate control efficiency with significant difference among different treatment groups at $p<0.05$.

Table 4. Curative activity of compound $5 \mathrm{t}$ against rice bacterial leaf blight.

\begin{tabular}{cccc}
\hline \multirow{2}{*}{ Treatment } & \multicolumn{3}{c}{ 14 Days after Spraying } \\
\cline { 2 - 4 } & Morbidity (\%) & Disease Index (\%) & Control Efficiency (\%) ${ }^{\mathbf{2}}$ \\
\hline $\mathbf{5 t}$ & 100 & 43.83 & $56.05 \pm 8.73^{\mathrm{a}}$ \\
Bismerthiazol & 100 & 56.31 & $43.65 \pm 7.98^{\mathrm{b}}$ \\
Thiodiazole copper & 100 & 49.60 & $48.60 \pm 5.14^{\mathrm{b}}$ \\
CK $^{1}$ & 100 & 89.11 & - \\
\hline
\end{tabular}

${ }^{1}$ Negative control. ${ }^{2}$ Average of three replicates. Statistical analysis was performed by analysis of variance (ANOVA) in SPSS 17.0 software with equal variances assumed $(p>0.05)$ and equal variances not assumed $(p<0.05)$. The different lowercase letters indicate control efficiency with significant difference among different treatment groups at $p<0.05$.

\subsubsection{In Vivo Antibacterial Activities Against Xoc}

As shown in Figure 3a and Table 5, the target compound 5t exerted good in vivo protective activity $(58.22 \%)$ against rice bacterial leaf streak at $200 \mu \mathrm{g} / \mathrm{mL}$ concentration, which was better than thiodiazole copper (53.77\%) and bismerthiazol (46.08\%). Meanwhile, Figure $3 \mathrm{~b}$ and Table 6 show that compound $5 \mathrm{t}$ had good in vivo curative activity against rice bacterial leaf streak. The control efficiency was $55.92 \%$, which was higher than those of thiodiazole copper (42.83\%) and bismerthiazol (45.25\%).

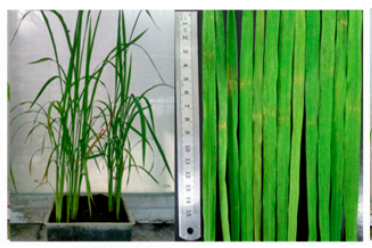

Thiodiazole copper

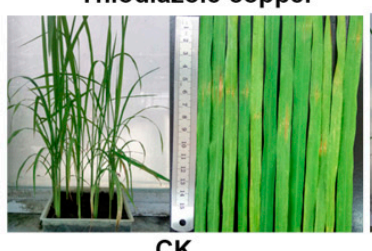

CK

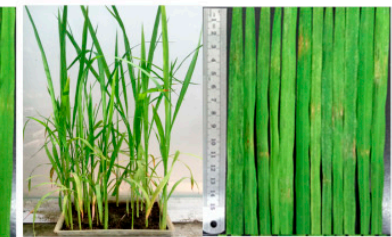

Bismerthiazol

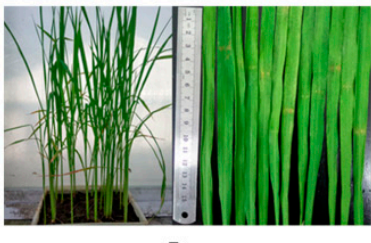

$5 t$

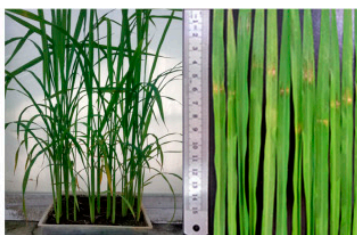

Thiodiazole copper

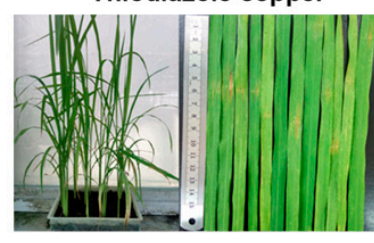

CK

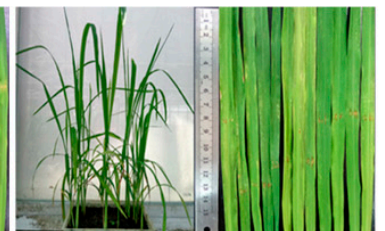

Bismerthiazol

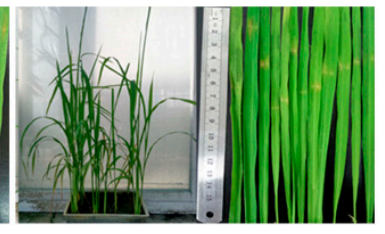

$5 t$

b

Figure 3. Protective (a) and curative (b) activities of compound $5 \mathbf{t}$ against rice bacterial leaf streak. 
Table 5. Protective activity of compound $\mathbf{5 t}$ against rice bacterial leaf streak.

\begin{tabular}{cccc}
\hline \multirow{2}{*}{ Treatment } & \multicolumn{3}{c}{ 14 Days after Spraying } \\
\cline { 2 - 4 } & Morbidity (\%) & Disease Index (\%) & Control Efficiency (\%) ${ }^{\mathbf{2}}$ \\
\hline 5t & 100 & 38.11 & $58.22 \pm 9.93^{\mathrm{a}}$ \\
Bismerthiazol & 100 & 48.75 & $46.08 \pm 6.62^{\mathrm{c}}$ \\
Thiodiazole copper & 100 & 42.75 & $53.77 \pm 6.89^{\mathrm{b}}$ \\
CK $^{1}$ & 100 & 81.50 & - \\
\hline
\end{tabular}

${ }^{1}$ Negative control. ${ }^{2}$ Average of three replicates. Statistical analysis was performed by analysis of variance (ANOVA) in SPSS 17.0 software with equal variances assumed $(p>0.05)$ and equal variances not assumed $(p<0.05)$. The different lowercase letters indicate control efficiency with significant difference among different treatment groups at $p<0.05$.

Table 6. Curative activity of compound $\mathbf{5 t}$ against rice bacterial leaf streak.

\begin{tabular}{cccc}
\hline \multirow{2}{*}{ Treatment } & \multicolumn{3}{c}{ 14 Days after Spraying } \\
\cline { 2 - 4 } & Morbidity (\%) & Disease Index (\%) & Control Efficiency (\%) ${ }^{\mathbf{2}}$ \\
\hline 5t & 100 & 46.20 & $55.92 \pm 10.34^{\mathrm{a}}$ \\
Bismerthiazol & 100 & 57.35 & $45.25 \pm 5.26^{\mathrm{c}}$ \\
Thiodiazole copper & 100 & 53.80 & $42.83 \pm 9.55^{\mathrm{c}}$ \\
CK $^{1}$ & 100 & 83.30 & - \\
\hline
\end{tabular}

${ }^{1}$ Negative control. ${ }^{2}$ Average of three replicates. Statistical analysis was performed by analysis of variance (ANOVA) in SPSS 17.0 software with equal variances assumed $(p>0.05)$ and equal variances not assumed $(p<0.05)$. The different lowercase letters indicate control efficiency with significant difference among different treatment groups at $p<0.05$.

\subsection{Real-Time Quantitative PCR Assays}

The fluorescence amplification curve (Figure $4 a, d$ ), melting curve (Figure $4 b, e$ ) and standard curve (Figure 4c,f) of known concentration Xoo and Xoc cultures are shown in Figure 4. Melting curve analysis showed a single peak for each primer at around $88^{\circ} \mathrm{C}$ and $85^{\circ} \mathrm{C}$ (Figure $4 \mathrm{~b}, \mathrm{e}$ ) suggesting the absence of primer dimers. The standard curve of Xoo and Xoc (Figure 4c,f) is $\mathrm{y}=-2.001 \mathrm{x}+41.446$ and $\mathrm{y}=-1.8829 \mathrm{x}+40.694$, and the $R^{2}$ is 0.9888 and 0.9822 , respectively.
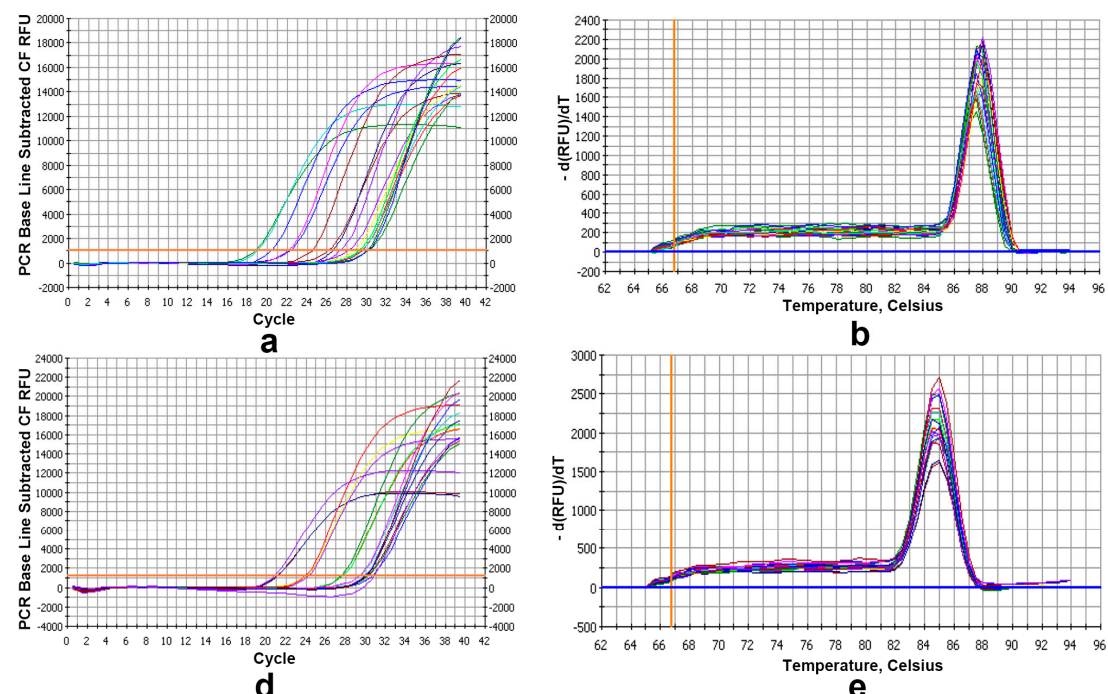

b

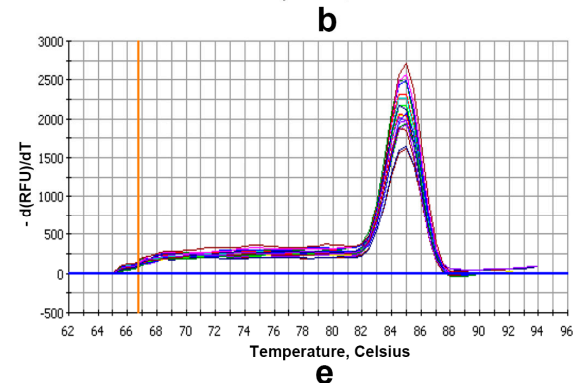

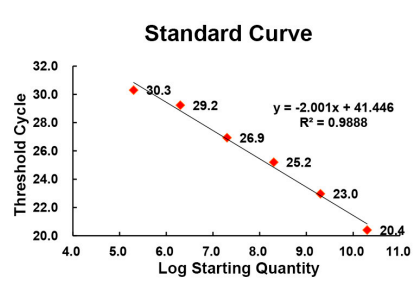

C

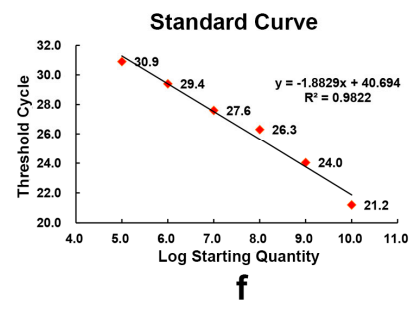

Figure 4. Fluorescence amplification curve (a), melting curve (b), and standard curve (c) of Xoo; fluorescence amplification curve (d), melting curve (e), and standard curve (f) of Xoc.

The Xoo and Xoc titer in rice leaves are shown in Tables 7 and 8 according to the treatment sample threshold cycle value and the standard curve. As shown in Table 7, the titer of Xoo in the rice leaves 
was $2.42 \times 10^{11} \mathrm{CFU} / \mathrm{mL}$ after with the compound $5 \mathbf{t}$ in protective treatment, which was lower than negative control $\left(1.04 \times 10^{12} \mathrm{CFU} / \mathrm{mL}\right)$ and positive controls (thiodiazole copper: $3.05 \times 10^{11} \mathrm{CFU} / \mathrm{mL}$, bismerthiazol: $3.42 \times 10^{11} \mathrm{CFU} / \mathrm{mL}$ ), and the titer of Xoo in the rice leaves was $3.05 \times 10^{11} \mathrm{CFU} / \mathrm{mL}$ in curative treatment, which was lower than that of the negative $\left(1.26 \times 10^{12} \mathrm{CFU} / \mathrm{mL}\right)$ and positive (thiodiazole copper: $3.69 \times 10^{11} \mathrm{CFU} / \mathrm{mL}$, bismerthiazol: $4.83 \times 10^{11} \mathrm{CFU} / \mathrm{mL}$ ) controls.

Table 7. The Xoo titer in the rice leaves treated by compound $5 \mathbf{t}$.

\begin{tabular}{ccccc}
\hline \multirow{2}{*}{ Compound } & \multicolumn{2}{c}{ Protective Treatment } & \multicolumn{2}{c}{ Curative Treatment } \\
\cline { 2 - 5 } & Ct $^{\mathbf{1}}$ & Titer $^{\mathbf{2}} \mathbf{( C F U / m L )}$ & Ct $^{\mathbf{1}}$ & Titer $^{\mathbf{2}} \mathbf{( C F U / m L )}$ \\
\hline $\mathbf{5 t}$ & $18.67 \pm 1.76$ & $2.42 \times 10^{11}$ & $18.47 \pm 1.19$ & $3.05 \times 10^{11}$ \\
Thiodiazole copper & $18.47 \pm 1.27$ & $3.05 \times 10^{11}$ & $18.30 \pm 1.21$ & $3.69 \times 10^{11}$ \\
Bismerthiazol & $18.37 \pm 1.68$ & $3.42 \times 10^{11}$ & $18.07 \pm 0.60$ & $4.83 \times 10^{11}$ \\
CK $^{3}$ & $17.40 \pm 0.62$ & $1.04 \times 10^{12}$ & $17.23 \pm 0.25$ & $1.26 \times 10^{12}$ \\
\hline
\end{tabular}

${ }^{1}$ Average threshold cycle of three replicates. ${ }^{2}$ Xoo titer in the rice leaves. ${ }^{3}$ Negative control.

As shown in Table 8, in the protective and curative experiment, the titer of Xoc in the rice leaves treated with compound $5 \mathbf{t}$ were $2.55 \times 10^{10} \mathrm{CFU} / \mathrm{mL}$ and $7.35 \times 10^{10} \mathrm{CFU} / \mathrm{mL}$, respectively, which were lower than the negative controls $\left(1.20 \times 10^{11}\right.$ and $\left.1.41 \times 10^{11} \mathrm{CFU} / \mathrm{mL}\right)$ and the positive controls (thiodiazole copper: $3.83 \times 10^{10}$ and $8.31 \times 10^{10} \mathrm{CFU} / \mathrm{mL}$, bismerthiazol: $4.16 \times 10^{10}$ and $7.98 \times 10^{10} \mathrm{CFU} / \mathrm{mL}$ ).

Table 8. The Xoc titer in the rice leaves treated by compound $5 \mathbf{t}$.

\begin{tabular}{ccccc}
\hline \multirow{2}{*}{ Compound } & \multicolumn{2}{c}{ Protective Treatment } & \multicolumn{2}{c}{ Curative Treatment } \\
\cline { 2 - 5 } & Ct $^{\mathbf{1}}$ & Titer $^{\mathbf{2}} \mathbf{( C F U / m L )}$ & Ct $^{\mathbf{1}}$ & Titer $^{\mathbf{2}} \mathbf{( C F U / m L )}$ \\
\hline $\mathbf{5 t}$ & $21.10 \pm 0.66$ & $2.55 \times 10^{10}$ & $20.23 \pm 0.25$ & $7.35 \times 10^{10}$ \\
Thiodiazole copper & $20.77 \pm 0.21$ & $3.83 \times 10^{10}$ & $20.13 \pm 0.81$ & $8.31 \times 10^{10}$ \\
Bismerthiazol & $20.70 \pm 0.26$ & $4.16 \times 10^{10}$ & $20.17 \pm 0.38$ & $7.98 \times 10^{10}$ \\
CK $^{3}$ & $19.83 \pm 0.25$ & $1.20 \times 10^{11}$ & $19.70 \pm 0.46$ & $1.41 \times 10^{11}$ \\
\hline
\end{tabular}

${ }^{1}$ Average threshold cycle of three replicates. ${ }^{2}$ Xoc titer in the rice leaves. ${ }^{3}$ Negative control.

\subsection{Study of 3D-QSAR Models}

The bioactivity data for title compounds against Xoo are shown as $\mathrm{pEC}_{50}$ (Table 9) and used for 3D-QSAR analysis. The training set of the comparative molecular field analysis (CoMFA) and comparative molecular similarity indices analysis (CoMSIA) models were generated. This training set contained 25 compounds by selecting randomly from all title compounds, whereas the remaining six (asterisk-labeled) compounds were used as the testing set. The SYBYL-X 2.1 software (Tripos Inc., St. Louis, MO, USA) was used to carry out molecular modeling. The Gasteiger-Hückel charge, Tripos force field, and Powell conjugate gradient algorithm were used to optimize the structure. The convergence criterion was $0.005 \mathrm{kcal} / \mathrm{mol}$. For the CoMFA and CoMSIA modeling studies, the 3D structure of 31 molecules was aligned on a common template molecule with $5 \mathbf{t}$, which has the best bactericidal activity against Xoo. The alignment result is shown in Figure 5.

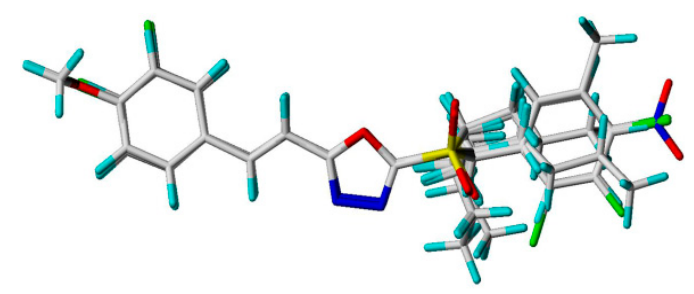

Figure 5. Alignment of training compounds. 
The $\mathrm{pEC}_{50}$ value and the parameters of the models were analyzed by partial least squares (PLS) regression. First, leave-one-out cross-validation was performed on the training set compounds. The optimal number of components (ONCs) and the cross-validation coefficient $\left(q^{2}\right)$ were obtained in this step. Then, no validation was performed to verify the fitting ability and other properties of the model. The non-cross-validated correlation coefficient $\left(r^{2}\right), F$ value, standard error of estimate (SEE) value, and the field-to-activity contribution value were acquired in the terminal panel when the PLS regression was completed.

Structure-activity relationship was discussed by utilizing the 3D-QSAR models created by CoMFA and CoMSIA. The CoMFA and CoMSIA models were constructed using the bioactivity data of Xoo. The relevant parameters of the model are listed in Table 10. Generally, the internal validation of cross-validated $q^{2}$ and the non-cross-validation coefficient $r^{2}$ values represent the robustness and predictive ability of the 3D-QSAR model. In addition, a satisfactory model has a commonly recognized value of $q^{2}>0.5$ and $r^{2}>0.8$. Table 10 shows that the $q^{2}$ of the CoMFA model was 0.725 , the corresponding $r^{2}$ was 0.963 , the SEE was 0.114 , and the $F$ value was 78.624 . The $q^{2}$ of the CoMSIA model was 0.707 , the $r^{2}$ was 0.941 , the SEE was 0.144 , and the $F$ value was 48.186 . This result shows that the model had a good predictive ability. As shown in Table 10, the contributions of steric and electrostatic fields to the CoMFA model were $65.1 \%$ and $34.9 \%$, respectively, indicating that bioactivity was mainly determined by steric interaction. The steric, electrostatic, hydrophobic, H-bond donor, and H-bond acceptor contributions of the CoMSIA models were 15.6\%, 32.9\%, $47.2 \%, 0.0 \%$, and $4.2 \%$, respectively, indicating that the target compound biological activity was mainly affected by the hydrophobic and electrostatic effects.

Table 9. Experimental and predicted results of $\mathrm{pEC}_{50}$ for CoMFA and CoMSIA.

\begin{tabular}{|c|c|c|c|c|c|c|}
\hline \multirow{2}{*}{ Compound } & \multirow{2}{*}{$\mathrm{EC}_{50}(\mu \mathrm{g} / \mathrm{mL})$} & \multirow{2}{*}{$\operatorname{Exp}^{a}$} & \multicolumn{2}{|c|}{ CoMFA } & \multicolumn{2}{|c|}{ CoMSIA } \\
\hline & & & Pred. $^{b}$ & Res. $^{c}$ & Pred. ${ }^{d}$ & Res. $^{c}$ \\
\hline $5 a$ & 3.74 & 4.825 & 4.769 & -0.056 & 4.824 & -0.001 \\
\hline $5 b$ * & 3.43 & 4.886 & 5.201 & 0.314 & 5.124 & 0.238 \\
\hline $5 c$ & 2.08 & 5.126 & 5.179 & 0.053 & 5.153 & 0.027 \\
\hline $5 d$ & 1.15 & 5.383 & 5.175 & -0.209 & 5.158 & -0.225 \\
\hline $5 e^{*}$ & 1.76 & 5.220 & 5.166 & -0.054 & 5.072 & -0.148 \\
\hline $5 f$ & 3.60 & 4.909 & 4.902 & -0.007 & 4.875 & -0.034 \\
\hline $5 g$ & 5.06 & 4.761 & 4.790 & 0.029 & 4.891 & 0.129 \\
\hline $5 \mathrm{~h} *$ & 8.07 & 4.579 & 4.876 & 0.279 & 4.635 & 0.056 \\
\hline $5 i$ & 1.75 & 5.185 & 5.102 & -0.083 & 5.157 & -0.028 \\
\hline $5 j$ & 2.38 & 5.074 & 5.187 & 0.113 & 5.190 & 0.116 \\
\hline $5 k$ & 0.61 & 5.686 & 5.647 & -0.039 & 5.548 & -0.138 \\
\hline 51 & 11.83 & 4.438 & 4.458 & 0.020 & 4.338 & -0.104 \\
\hline $5 \mathrm{~m} *$ & 2.28 & 5.070 & 5.238 & 0.168 & 5.272 & 0.201 \\
\hline $5 n$ & 1.67 & 5.228 & 5.322 & 0.094 & 5.305 & 0.078 \\
\hline 50 & 1.42 & 5.319 & 5.486 & 0.167 & 5.598 & 0.279 \\
\hline $5 p$ & 1.53 & 5.326 & 5.348 & 0.022 & 5.292 & -0.034 \\
\hline $5 q$ & 0.72 & 5.596 & 5.589 & -0.007 & 5.535 & -0.061 \\
\hline $5 r$ & 0.58 & 5.711 & 5.678 & -0.033 & 5.570 & -0.141 \\
\hline $5 s$ & 0.97 & 5.529 & 5.696 & 0.167 & 5.767 & 0.238 \\
\hline $5 t$ & 0.44 & 5.891 & 5.782 & -0.109 & 5.799 & -0.091 \\
\hline $5 \mathbf{u}$ & 2.66 & 5.022 & 4.926 & -0.096 & 4.936 & -0.087 \\
\hline $5 v^{*}$ & 1.93 & 5.183 & 5.012 & -0.171 & 4.969 & -0.214 \\
\hline $5 w$ & 22.74 & 4.157 & 4.251 & 0.094 & 4.310 & 0.154 \\
\hline $5 x$ & 3.95 & 4.940 & 4.733 & -0.207 & 4.753 & -0.187 \\
\hline $5 y$ & 20.95 & 4.210 & 4.240 & 0.029 & 4.251 & 0.040 \\
\hline $5 z$ & 19.92 & 4.238 & 4.159 & -0.079 & 4.226 & -0.012 \\
\hline $5 a a$ & 15.94 & 4.370 & 4.452 & 0.082 & 4.481 & 0.111 \\
\hline $5 \mathrm{ab}$ & 19.34 & 4.270 & 4.353 & 0.083 & 4.258 & -0.012 \\
\hline $5 a c$ & 4.43 & 4.949 & 4.959 & 0.010 & 4.986 & 0.037 \\
\hline $5 \mathrm{ad}$ & 1.36 & 5.481 & 5.441 & -0.040 & 5.426 & -0.055 \\
\hline $5 \mathrm{ae}^{*}$ & 4.00 & 4.967 & 4.403 & -0.565 & 4.795 & -0.173 \\
\hline
\end{tabular}

a Experimental $\mathrm{pEC}_{50} .{ }^{\mathrm{b}}$ Predicted by comparative molecular field analysis (CoMFA). ${ }^{\mathrm{c}}$ Relative error of (experimental predicted). ${ }^{\mathrm{d}}$ Predicted by comparative molecular similarity indices analysis (CoMSIA). ${ }^{*}$ The sample of the test set. 
Meanwhile, Table 9 illustrates the actual $\mathrm{pEC}_{50}$ of the model and the predicted $\mathrm{pEC}_{50}$. The residual between the actual biological activity of the compound and the predicted biological activity is very small, indicating that the model has certain predictive ability. Figure 6 shows the linear relationships between the actual value and the predicted value. The $r^{2}$ of the CoMFA and CoMSIA models are 0.9633 and 0.9416 , respectively. All data are concentrated near the straight line, indicating that the model has good correlation.

Table 10. Statistical parameters for the CoMFA and CoMSIA models.

\begin{tabular}{cccc}
\hline Statistical parameter & CoMFA & CoMSIA & Validation criterion \\
\hline$q^{2 \mathrm{a}}$ & 0.725 & 0.707 & $>0.5$ \\
ONC $^{\mathrm{b}}$ & 6 & 6 & $>0.8$ \\
$\mathrm{r}^{2 \mathrm{c}}$ & 0.963 & 0.941 & $<0.3$ \\
SEE $\mathrm{d}$ & 0.114 & 0.144 & \\
F-value & 78.624 & 48.186 & \\
Fraction of field contributions: & & & \\
Steric & 0.651 & 0.156 & \\
Electrostatic & 0.349 & 0.329 & \\
Hydrophobic & & 0.472 & \\
H-bond donor & & 0.000 & \\
H-bond acceptor & & 0.042 &
\end{tabular}

${ }^{\text {a }}$ Cross-validated correlation. ${ }^{\mathrm{b}}$ Optimum number of components. ${ }^{\mathrm{c}}$ Non-cross-validated correlation. ${ }^{\mathrm{d}}$ Standard error of estimate.
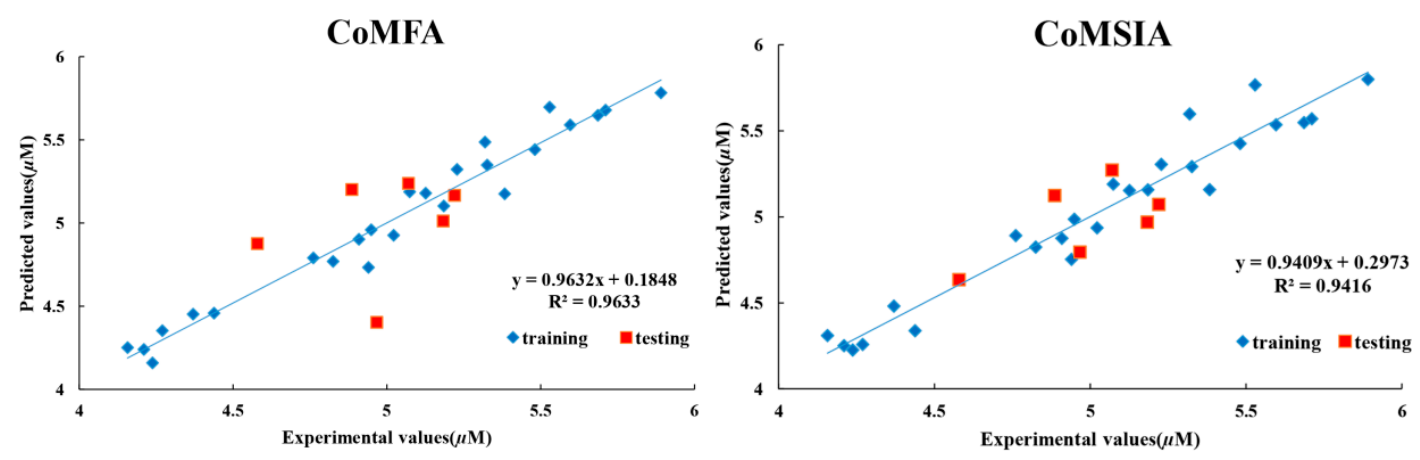

Figure 6. Plot of experimental and predicted $\mathrm{pLC}_{50}$ for the CoMFA and CoMSIA models.

Figure 7 shows the contour maps for the CoMFA model. The steric CoMFA map (Figure 7a) shows a green contour and indicates that the bulky groups would increase the activity. By contrast, yellow indicates the contour regions where the small groups would increase the activity. Therefore, a green block is present in the para position of the benzene ring, which indicates that a large substituted group should be introduced at this position. On the contrary, the yellow contour indicates that the introduction of small groups at this position is advantageous for enhancing the biological activity. Compounds having 4-F, 4-Cl, and 4- $\mathrm{Br}$ introduced at position $\mathrm{R}^{1}$ are superior to those without substituents, and for the halogen at the $\mathrm{R}^{1}$ position, a regularity of $4-\mathrm{Br}>4-\mathrm{Cl}>4-\mathrm{F}$, for example, $5 t>5 r>5 n>5 b$, is present. Moreover, ethyl activity is introduced at position $R^{2}$ better than $n$-pentyl, such as $\mathbf{5 b}>\mathbf{5 h}$. As shown in the electrostatic CoMFA map (Figure $7 \mathrm{~b}$ ), a red module is present at the para position of the benzene ring, which indicates that the introduction of the negative-charged group is conducive to improve the biological activity, and a blue module is present near other positions of the benzene ring. For example, the introduction of $4-\mathrm{F}$ compound $\mathbf{5 n}$ is more active than the compound $\mathbf{5 j}$. 


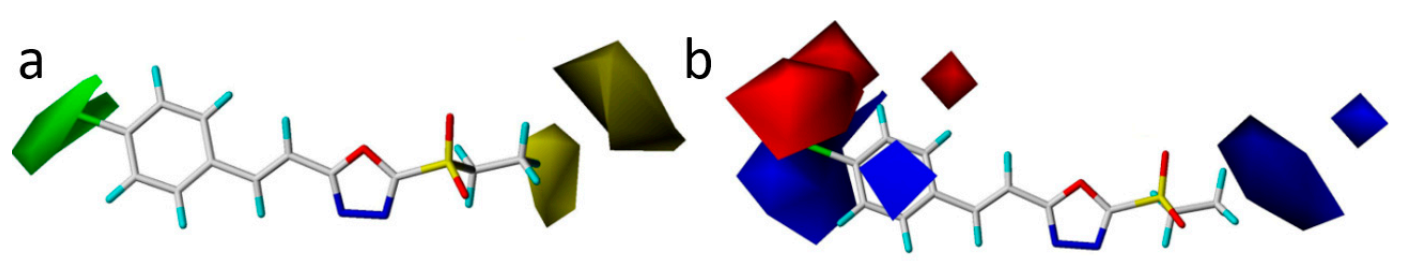

Figure 7. CoMFA contour maps of steric (a) and electrostatic (b) fields.

The $\mathrm{R}^{1}$ position in the steric field of the CoMSIA model (Figure 8a) has roughly the same effect on the biological activity of the compound as that of the CoMFA model. Moreover, the $\mathrm{R}^{2}$ position elaborates the relationship of the biological activity of the compound in further detail. The green and yellow modules near the sulfone group indicate that the $\mathrm{R}^{2}$ position shows a tendency of increasing first and then decreasing as the group increases in activity, for example, $\mathbf{5 a}<\mathbf{5 c}, \mathbf{5 h}<\mathbf{5 c}$, and $\mathbf{5 w}<\mathbf{5 c}$. As shown by the effects of the electrostatic field from the CoMSIA model (Figure $8 b$ ), the red module indicates that the introduction of a strong electronegative group will enhance the activity, whereas the blue module indicates that the introduction of a positive group is conducive to activity enhancement, for example, $\mathbf{5 y}>\mathbf{5 w}$. The hydrophobic CoMSIA map (Figure 8c) shows that the yellow portion shown at the $\mathrm{R}^{1}$ position indicates that the introduction of a hydrophilic group favors activity, while the gray portion indicated by the $\mathrm{R}^{2}$ position indicates that introduction of a hydrophobic group facilitates activity. The H-bond acceptor CoMSIA map (Figure 8d) shows the purple part and indicates that the addition of a hydrogen bond acceptor favors activity, whereas the red outline indicates that an increase of hydrogen bond donors does not favor activity. The introduction of a hydrogen acceptor at the red moiety near the benzene ring will decrease the biological activity, whereas the introduction of a hydrogen acceptor at the oxadiazole purple moiety increases the biological activity. This also explains why compound $\mathbf{5 q}$ shows better bactericidal activity than $\mathbf{5 u}$.

a

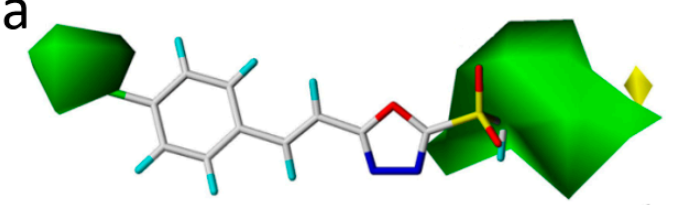

C

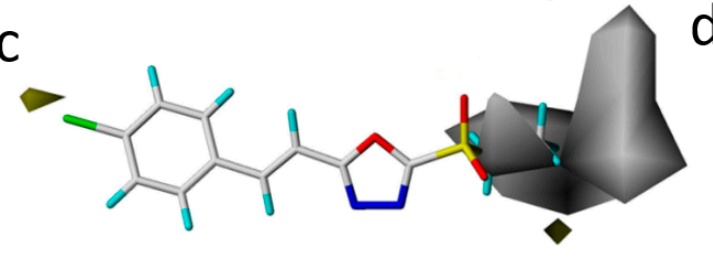

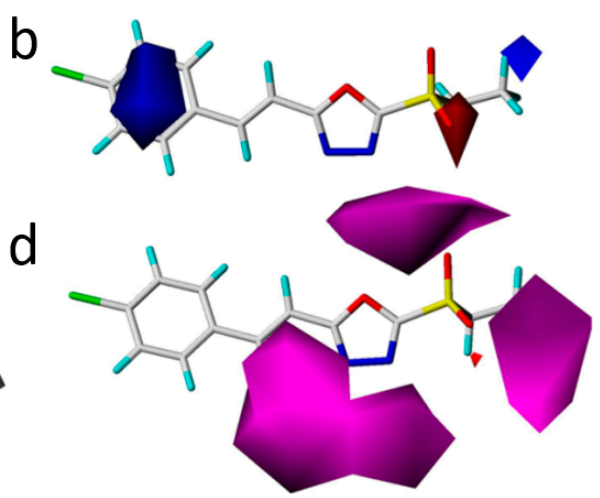

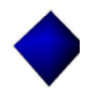

Figure 8. CoMSIA contour maps of steric (a), electrostatic (b), hydrophobic (c), and H-bond acceptor (d) fields.

\section{Discussion}

In our present work, an unsaturated double bond was added between the benzene ring and the 1,3,4-oxadiazole, that is, combining 1,3,4-oxadiazole with cinnamic acid to form novel 1,3,4-oxadiazole derivatives containing a cinnamic acid moiety. This bond can enhance the antibacterial activities to introduce the double bond in 1,3,4-oxadiazole derivatives. Compounds $\mathbf{5 r}$ and $\mathbf{5 t}$ showed excellent antibacterial activities against $\mathrm{Xoo}$ and $\mathrm{Xoc}$ in vitro with $\mathrm{EC}_{50}$ values of 0.58 and 0.34 , and 0.44 and $0.20 \mu \mathrm{g} / \mathrm{mL}$, respectively, which were better than leading compounds cinnamic acid (236.07 and $270.45 \mu \mathrm{g} / \mathrm{mL}), \mathbf{a}(1.41$ and $2.01 \mu \mathrm{g} / \mathrm{mL})$, and $\mathbf{b}(0.84$ and $1.16 \mu \mathrm{g} / \mathrm{mL})$. Moreover, compound $5 \mathbf{t}$ had good in vivo protective and curative activity against rice bacterial leaf blight and rice bacterial leaf streak. Meanwhile, the in vivo efficacy of the compounds was demonstrated by real-time quantitative PCR to quantify bacterial titers. In addition, the 3D-QSAR model showed satisfactory predictive ability, 
and the results illuminated (as shown in Figure 9) that bulky groups, negatively charged groups, hydrophilic groups at $\mathrm{R}^{1}$ position, and small groups, positive groups, hydrophobic groups, $\mathrm{H}$-bond acceptor groups at the $\mathrm{R}^{2}$ position favor activity. Meanwhile the sulfone group is the essentially active group. These results provide further valuable clues for the design of novel 1,3,4-oxadiazole derivatives containing a cinnamic acid moiety.

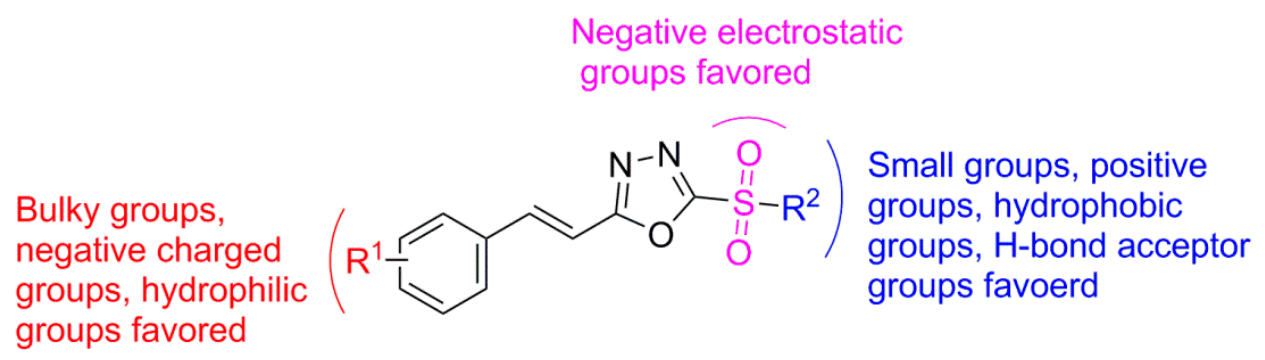

Figure 9. The structure-activity relationship (SAR) summarized based on our work.

\section{Materials and Methods}

\subsection{Materials and Instrument}

Cinnamic acids, 1-Ethyl-3-(3-dimethylaminopropyl) carb-odiimide hydrochloride (EDCI) and 1-hydroxybeonztriazole (HOBt) were purchased from Shanghai Tansoole Chemicals Co., Ltd (Shanghai, China). Other reagents and solvents were purchased from Guiyang Yuda Chemical Reagent Co., Ltd (Guizhou, China). All reagents and solvents were reagent grade and used without further purification.

Melting points were determined using an X-4 micro digital melting point (Beijing Tech Instruments Co., Beijing, China), and readings were uncorrected. ${ }^{1} \mathrm{H}$ NMR and ${ }^{13} \mathrm{C}$ NMR spectra were recorded on a JEOL-500 NMR spectrometer (JEOL, Tokyo, Japan) with DMSO- $\mathrm{d}_{6}$ or $\mathrm{CDCl}_{3}$ as solvent and TMS as internal standard. High-resolution mass spectra (ESI TOF $(+)$ ) were measured on a Thermo Fisher Scientific LTQ Orbitrap XL (Waltham, MA, USA). The real-time quantitative PCR experiment was carried out on the instrument of BIO-RAD iCycle which was purchased from Bio-Rad Laboratories, Inc (Hercules, MO, USA). The CoMFA and CoMSIA models were analyzed using SYBYL-X 2.1 (Tripos Inc., St. Louis, MO, USA).

\subsection{Chemistry}

\subsubsection{General Procedure for the Synthesis of Intermediates 2 and 3}

Intermediate $\mathbf{2}$ was prepared according to the known method [29]. Intermediate $\mathbf{3}$ was prepared according to the following method. Carbon disulfide $(0.75 \mathrm{~mol})$ was slowly added dropwise to a three-necked flask containing $\mathrm{KOH}(0.6 \mathrm{~mol})$ of ethanol $(500 \mathrm{~mL})$ at room temperature to form potassium ethylxanthate. Then, intermediate $2(0.5 \mathrm{~mol})$ was added, and the reaction was heated to $40-50{ }^{\circ} \mathrm{C}$ and heated to reflux. After the reaction was completed, the reaction mixture was spin-dried to remove the solvent ethanol to give a dark-brown powdery solid in $85-90 \%$ yields.

\subsubsection{General Procedure for the Synthesis of Intermediate 4}

Intermediate $3(1.0 \mathrm{mmol})$ and potassium carbonate $(3.0 \mathrm{mmol})$ were added to a three-necked flask containing dimethylformamide (DMF) $8 \mathrm{~mL}$ and stirred at room temperature. Then, $\mathrm{R}_{2} \mathrm{X}(1.1 \mathrm{mmol})$ was slowly added dropwise. The mixture was heated to $70-80^{\circ} \mathrm{C}$ and stirred continuously for $3-5 \mathrm{~h}$. After the reaction was completed and cooled to $20-25^{\circ} \mathrm{C}$, the reaction solution was dropped into water, stirred, and dispersed, and filtered to obtain a yellow solid powder intermediate 4 . 


\subsubsection{General Procedure for the Title Compounds 5a-5ae}

The title compounds were prepared following the reported methods [30]. Intermediate 4 (1 mmol) was dissolved in ethanol $(10 \mathrm{~mL})$. Then, a solution of ammonium molybdate $(0.2 \mathrm{mmol})$ in $30 \%$ hydrogen peroxide ( $20 \mathrm{mmol}$ ) was added and stirred for $5 \mathrm{~h}$ (as monitored by TLC). The solvent was removed under vacuum, and a saturated aqueous solution of sodium bicarbonate was added to adjust the $\mathrm{pH}$ to 8-9. Then, the mixture was extracted with $\mathrm{CH}_{2} \mathrm{Cl}_{2}$, and the solvent was dried and evaporated under reduced pressure to obtain a yellow solid. The crude product was also recrystallized from ethanol to obtain the pure target compounds 5a-5ae in 48.9-89.3\% yields. The physical, NMR, and HRMS data of title compounds were listed in supplementary materials.

\subsection{In Vitro Antibacterial Activity}

The title compounds 5a-5ae were determined for in vitro antibacterial activities against Xoo and Xoc using the turbidimeter test [31]. The test solutions of 50 and $5 \mu \mathrm{g} / \mathrm{mL}$ were prepared by dissolving the title compound in dimethylsulfoxide (DMSO) and diluting with $0.1 \%$ Tween-20 in sterile distilled water. Thiodiazole copper ( $20 \%$ suspension concentrate) and bismerthiazol ( $20 \%$ wettable powder) were used as a positive control. The DMSO was used as a negative control. Approximately $4 \mathrm{~mL}$ of nutrient broth (NB) media was added with $1 \mathrm{~mL}$ test solution and $40-\mu \mathrm{L}$ culture solutions containing the pathogens of Xoo or Xoc. The inoculated tubes were incubated for $36-48 \mathrm{~h}$ at $180 \mathrm{rpm}$ and $28 \pm 1{ }^{\circ} \mathrm{C}$ in a constant temperature shaker. Cultures were monitored for growth on the microplate reader by measuring the optical density at $595 \mathrm{~nm}$ (OD 595) until the bacteria in the untreated nutrient broth (NB) media were in logarithmic growth.

$$
\text { Inhibition rate }(\%)=(\text { untreated }- \text { treated }) / \text { untreated } \times 100
$$

The results of antibacterial activities of the target compounds against Xoo and Xoc were expressed by $\mathrm{EC}_{50}$ and were evaluated by SPSS17.0 software. The experiment was repeated three times for each compound.

\subsection{In Vivo Antibacterial Activity}

\subsubsection{In Vivo Antibacterial Activities Against Rice Bacterial Leaf Blight}

Potted plants were used to determine the in vivo protection and curative activity of compounds under greenhouse conditions according to previously reported methods [23]. Target compound $\mathbf{5 t}$ was tested for their protective activities. Bismerthiazol and thiodiazole copper were used as positive controls. After the "Fengyouxiangzhan" rice seeds were sowed at approximately one and a half months, the test compound dissolved in DMSO was diluted to a concentration of $200 \mu \mathrm{g} / \mathrm{mL}$ by $0.1 \%$ Tween-20 water. Sterile distilled water was used in the negative control. The liquid water was evenly sprayed on rice leaves. After one day, a $2-3 \mathrm{~cm}$ section of the rice leaf tip was cut, and the wound site was soaked in the bacterial solution for $5 \mathrm{~s}$. At the same time, 10 leaves were treated at a time, and the process was repeated three times. After the rice leaves were inoculated at approximately 14 days, the control effect and disease index of inoculated rice leaves were evaluated.

In the same way, compound $\mathbf{5 t}$ was tested for their curative activities. Thiodiazole copper and bismerthiazol were used as positive controls. After the "Fengyouxiangzhan" rice seeds were sowed at approximately one and a half months, a $2-3 \mathrm{~cm}$ section of rice leaf tip was cut, and the wound site was soaked in the bacterial solution for $5 \mathrm{~s}$. After one day of inoculation, a solution of the compound containing $200 \mu \mathrm{g} / \mathrm{mL}$ of formulation was sprayed on the rice leaves, whereas $0.1 \%$ Tween-20 water was sprayed onto the negative control rice leaves. Ten leaves were also treated at a time, and the procedure was repeated three times. After the rice leaves were inoculated at approximately 14 days, the control effect and disease index of the inoculated rice leaves were measured. The degree of disease was graded as follows: level 0 , no onset; level 1, lesions accounted for 1-15\% of leaf area; level 2, lesions 
accounted for $16-30 \%$ of leaf area; level 3, lesions accounted for $31-50 \%$ of leaf area; level 4 , the lesions accounted for $51-75 \%$ of leaf area; and level 5 , the lesions accounted for $76-100 \%$ of leaf area.

Disease index $(\%)=(\Sigma$ (number of diseased plants $\times$ corresponding grade value $) /($ total number of diseased plants $\times$ maximum disease grade value) $) \times 100$

Control effect $(\%)=(($ disease index of the negative control - disease index of the treatment

group) $/$ (disease index of the negative control) $) \times 100$

Statistical analysis was performed by analysis of variance (ANOVA) in SPSS 17.0 software with equal variances assumed $(p>0.05)$ and equal variances not assumed $(p<0.05)$. The different lowercase letters shown in Tables 3-6 indicate control efficiency with significant difference among different treatment groups at $p<0.05$.

\subsubsection{In Vivo Antibacterial Activities Against Rice Bacterial Leaf Streak}

Potted plants were used to determine the in vivo protection and curative activity of compounds under greenhouse conditions by using the previously reported methods [32]. The target compound $\mathbf{5 t}$ was assayed for protective activity against rice bacterial leaf streak. Thiodiazole copper and bismerthiazol were used as positive controls. After the "Fengyouxiangzhan" rice seeds were sowed at approximately one and a half months, the test compound in DMSO was diluted with $0.1 \%$ Tween- 20 water to a concentration of $200 \mu \mathrm{g} / \mathrm{mL}$. Liquid water was evenly sprayed on the rice leaves, and the negative control rice leaves were sprayed with $0.1 \%$ Tween-20 water. Then, $1 / 3$ to $1 / 2$ of the tips of the leaf were pierced with acupuncture containing Xoc by acupuncture inoculation after spraying for one day, with four holes per leaf, 10 leaves per treatment, and three replicates. After the rice leaves were inoculated at approximately 21 days, the control effect and disease index of inoculated rice leaves were evaluated.

Similarly, the target compound $\mathbf{5 t}$ was assayed for curative activities against the rice bacterial leaf streak. Bismerthiazol and thiodiazole copper were used as positive controls. After the "Fengyouxiangzhan" rice seeds were sowed at approximately one and a half months, 1/3 to 1/2 of the tips of the leaf were pierced with acupuncture containing Xoc by acupuncture inoculation, with four holes per leaf. After one day, the dissolved test compound in DMSO was diluted with $0.1 \%$ Tween-20 water to a concentration of $200 \mu \mathrm{g} / \mathrm{mL}$. The liquid was evenly sprayed on the rice leaves, whereas $0.1 \%$ Tween- 20 water was used on the negative control rice. Ten leaves were treated at a time, and the procedure was repeated three times. After the rice leaves were inoculated at approximately 21 days, the control effect and disease index of inoculated rice leaves were evaluated. The degree of disease was graded as follows: level 0: no onset; level 1: lesions account for less than $1 \%$ of leaf area; level 3: lesions account for $1-5 \%$ of leaf area; level 5: lesions account for $6-25 \%$ of leaf area; level 7: lesions account for $26-50 \%$ of leaf area; level 9: lesions account for more than $50 \%$ of leaf area. The formula for calculating the disease index and control effect of rice bacterial leaf streak is the same as that of rice bacterial leaf blight.

\subsection{Real-Time Quantitative PCR Assays}

The titer of Xoo and Xoc in the rice leaves treated by compound $5 \mathbf{t}$ was quantified by using Synergy Brands (SYBR) Green real-time quantitative PCR assays. The Xoo and Xoc cultures were 10-fold serially diluted from $2.0 \times 10^{10}$ to $2.0 \times 10^{9}, 2.0 \times 10^{8}, 2.0 \times 10^{7}, 2.0 \times 10^{6}, 2.0 \times 10^{5}$ and from $1.0 \times 10^{10}$ to $1.0 \times 10^{9}, 1.0 \times 10^{8}, 1.0 \times 10^{7}, 1.0 \times 10^{6}, 1.0 \times 10^{5}$, then following the manufacturer's protocol of the TIANamp Bacteria DNA Kit (TIANGEN BIOTECH (BEIJING) CO., LTD) to extract the genomic DNA of these samples and used to produce standard curves. Genomic DNA of bacterial and leaf tissue was extracted according to the CTAB method [33]. The primers (Xoo230 F: 5'-CCTCTATGAGTCGGGAGCTG-3' / Xoo230 R: 5'-ACACCGTGATGCAATGAAGA-3' and Xoc112 F: 5'-CAAGACAGACATTGCTGGCA-3' / Xoc112 R: 5'-GGTCTGGAATTTGTACTCCG-3') and 
method were adopted to carry out real-time quantitative PCR assays [34]. Each PCR reaction contained $10 \mu \mathrm{L}$ TB Green Premix Ex Taq II (Tli RNaseH Plus) $(2 \times), 0.8 \mu \mathrm{L}$ forward primer $(10 \mu \mathrm{M}), 0.8 \mu \mathrm{L}$ reverse

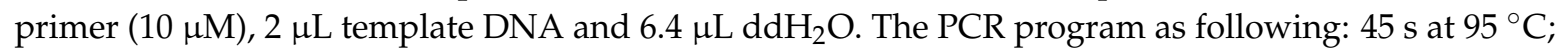
40 cycles of $5 \mathrm{~s}$ at $95^{\circ} \mathrm{C}, 30 \mathrm{~s}$ at $61^{\circ} \mathrm{C}$ and melting curve at $65^{\circ} \mathrm{C}$ to $95^{\circ} \mathrm{C}$ with increases of $0.5^{\circ} \mathrm{C}$.

\section{Conclusions}

In this work, 31 novel 1,3,4-oxadiazole derivatives containing a cinnamic acid moiety were designed and synthesized. All of the compounds exhibited good antibacterial activities. Among them, compounds $\mathbf{5 r}$ and $\mathbf{5 t}$ showed better antibacterial activities against Xoo and Xoc in vitro than commercial agents thiodiazole copper and bismerthiazol. In addition, compound $\mathbf{5 t}$ had good in vivo protective and curative activity against rice bacterial leaf blight and leaf streak. The 1,3,4-oxadiazole derivatives containing a cinnamic acid moiety can be used as potential new bactericides for rice bacterial diseases.

Supplementary Materials: Supplementary Materials can be found at http:/ /www.mdpi.com/1422-0067/20/5/1020/ s1.

Author Contributions: B.S., D.H., and S.W. conceived and designed the experiments; S.W. and C.Y. performed the experiments; B.S., D.H., S.W., Y.W.; S.L.; C.Y., J.C., F.H., and Y.Y. analyzed and interpreted the data; S.W. wrote the paper; B.S. and X.G. critically revised the paper with regard to important intellectual content; D.H.; X.G. and B.S. provided technical support and supervised the study; S.W., Y.W.; S.L.; C.Y., J.C., F.H., and Y.Y. provided material support. All authors have read and approved the final version of the manuscript.

Funding: This research was funded by the National Natural Science Foundation of China, grant number 21672044 and the National Key Research and Development Program of China, grant number 2017YFD0201404.

Conflicts of Interest: The authors declare no conflicts of interests.

\section{Abbreviations}

$\begin{array}{ll}\text { Xoo } & \text { Xanthomonas oryzae pv. Oryzae } \\ \text { Xoc } & \text { Xanthomonas oryzae pv. Oryzicola } \\ \text { EC }_{50} & \text { 50\% effective concentration } \\ \text { CoMFA } & \text { comparative molecular field analysis } \\ \text { CoMSIA } & \text { comparative molecular similarity index analysis } \\ \text { 3D-QSAR } & \text { three-dimensional quantitative structure-activity relationship } \\ \text { PLS } & \text { partial least squares } \\ \text { ONC } & \text { optimal number of components } \\ \text { SEE } & \text { standard error of estimate } \\ \text { OD595 } & \text { optical density at } 595 \mathrm{~nm}\end{array}$

\section{References}

1. Liu, W.D.; Liu, J.L.; Triplett, L.; Leach, J.E.; Wang, G.L. Novel insights into rice innate immunity against bacterial and fungal pathogens. Annu. Rev. Phytopathol. 2014, 52, 213-241. [CrossRef] [PubMed]

2. Ji, Z.Y.; Wang, C.L.; Zhao, K.J. Rice routes of countering Xanthomonas oryzae. Int. J. Mol. Sci. 2018, $19,3008$. [CrossRef] [PubMed]

3. Bae, N.; Park, H.J.; Park, H.; Kim, M.; Do, E.; Han, S.W. Elucidating functions of fleQ in Xanthomonas oryzae pv. oryzae by comparative proteomic and phenotypic analyses. Int. J. Mol. Sci. 2018, 19, 3038. [CrossRef]

4. Niño-Liu, D.O.; Ronald, P.C.; Bogdanove, A.J. Xanthomonas oryzae pathovars: Model pathogens of a model crop. Mol. Plant Pathol. 2006, 7, 303-324. [CrossRef] [PubMed]

5. Tariq, R.; Wang, C.L.; Qin, T.F.; Xu, F.F.; Tang, Y.C.; Gao, Y.; Ji, Z.Y.; Zhao, K.J. Comparative transcriptome profiling of rice near-isogenic line carrying Xa23 under infection of Xanthomonas oryzae pv. oryzae. Int. J. Mol. Sci. 2018, 19, 717. [CrossRef] [PubMed]

6. Chen, Y.; Yang, X.; Gu, C.Y.; Zhang, A.F.; Wang, W.X.; Gao, T.C.; Yao, J.; Yuan, S.K. Activity of a novel bactericide, zinc thiazole against Xanthomonas oryzae pv. oryzae in Anhui Province of China. Ann. Appl. Biol. 2015, 166, 129-135. [CrossRef] 
7. Wang, P.Y.; Zhou, L.; Zhou, J.; Wu, Z.B.; Xue, W.; Song, B.A.; Yang, S. Synthesis and antibacterial activity of pyridinium-tailored 2,5-substituted-1,3,4-oxadiazole thioether/sulfoxide/sulfone derivatives. Bioorg. Med. Chem. Lett. 2016, 26, 1214-1217. [CrossRef] [PubMed]

8. Li, P.; Shi, L.; Gao, M.N.; Yang, X.; Xue, W.; Jin, L.H.; Hu, D.Y.; Song, B.A. Antibacterial activities against rice bacterial leaf blight and tomato bacterial wilt of 2-mercapto-5-substituted-1,3,4-oxadiazole/thiadiazole derivatives. Bioorg. Med. Chem. Lett. 2015, 25, 481-484. [CrossRef] [PubMed]

9. El-Seedi, H.R.; El-Said, A.M.A.; Khalifa, S.A.M.; Göransson, U.; Bohlin, L.; Borg-Karlson, A.K.; Verpoorte, R. Biosynthesis, natural sources, dietary intake, pharmacokinetic properties, and biological activities of hydroxycinnamic acids. J. Agric. Food Chem. 2012, 60, 10877-10895. [CrossRef] [PubMed]

10. Heřmánková-Vavř́iková, E.; Křenková, A.; Petrásková, L.; Chambers, C.S.; Zápal, J.; Kuzma, M.; Valentová, K.; Křen, V. Synthesis and antiradical activity of isoquercitrin esters with aromatic acids and their homologues. Int. J. Mol. Sci. 2017, 18, 1074. [CrossRef] [PubMed]

11. Guitard, R.; Nardello-Rataj, V.; Aubry, J.M. Theoretical and kinetic tools for selecting effective antioxidants: Application to the protection of omega-3 oils with natural and synthetic phenols. Int. J. Mol. Sci. 2016, 17, 1220. [CrossRef] [PubMed]

12. Kai, Z.P.; Huang, J.; Xie, Y.; Tobe, S.S.; Ling, Y.; Zhang, L.; Zhao, Y.C.; Yang, X.L. Synthesis, biological activity, and hologram quantitative structure-activity relationships of novel allatostatin analogues. J. Agric. Food Chem. 2010, 58, 2652-2658. [CrossRef] [PubMed]

13. Gravina, H.D.; Tafuri, N.F.; Silva, J.A.; Fietto, J.L.R.; Oliveira, T.T.; Diaz, M.A.N.; Almeida, M.R. In vitro assessment of the antiviral potential of trans-cinnamic acid, quercetin and morin against equid herpesvirus 1. Res. Vet. Sci. 2011, 91, 158-162. [CrossRef] [PubMed]

14. Wu, Z.X.; Zhang, J.; Chen, J.X.; Pan, J.K.; Zhao, L.; Liu, D.Y.; Zhang, A.W.; Chen, J.; Hu, D.Y.; Song, B.A. Design, synthesis, antiviral bioactivity and three-dimensional quantitative structure-activity relationship study of novel ferulic acid ester derivatives containing quinazoline moiety. Pest Manag. Sci. 2017, 73, 2079-2089. [CrossRef] [PubMed]

15. Lei, K.; Sun, D.W.; Hua, X.W.; Tao, Y.Y.; Xu, X.H.; Kong, C.H. Synthesis, fungicidal activity and structure-activity relationships of 3-benzoyl-4-hydroxylcoumarin derivatives. Pest Manag. Sci. 2015, 72, 1381-1389. [CrossRef] [PubMed]

16. Wang, J.H.; Lou, J.F.; Luo, C.; Zhou, L.G.; Wang, M.G.; Wang, L. Phenolic compounds from halimodendron halodendron (pall.) voss and their antimicrobial and antioxidant activities. Int. J. Mol. Sci. 2012, 13, 11349-11364. [CrossRef] [PubMed]

17. Yang, C.F.; Zhou, Y.; Zheng, Y.; Li, C.L.; Sheng, S.; Wang, J.; Wu, F. Enzymatic modification of chitosan by cinnamic acids: Antibacterial activity against Ralstonia solanacearum. Int. J. Biol. Macromol. 2016, 87, 577-585. [CrossRef] [PubMed]

18. Vishnoi, S.; Agrawal, V.; Kasana, V.K. Synthesis and structure-activity relationships of substituted cinnamic acids and amide analogues: A new class of herbicides. J. Agric. Food Chem. 2009, 57, 3261-3265. [CrossRef] [PubMed]

19. Sova, M. Antioxidant and antimicrobial activities of cinnamic acid derivatives. Mini-Rev. Med. Chem. 2012, 12, 749-767. [CrossRef] [PubMed]

20. Anslow, P.A.; Stratford, M. Preservative and Flavoring System. U.S. Patent 6042861, 22 October 1998.

21. Li, P.; Tian, P.Y.; Chen, Y.Z.; Song, X.P.; Xue, W.; Jin, L.H.; Hu, D.Y.; Yang, S.; Song, B.A. Novel bisthioether derivatives containing a 1,3,4-oxadiazole moiety: Design, synthesis, antibacterial and nematocidal activities. Pest Manag. Sci. 2018, 74, 844-852. [CrossRef] [PubMed]

22. Xu, W.M.; Han, F.F.; He, M.; Hu, D.Y.; He, J.; Yang, S.; Song, B.A. Inhibition of tobacco bacterial wilt with sulfone derivatives containing an 1,3,4-oxadiazole moiety. J. Agric. Food Chem. 2012, 60, 1036-1041. [CrossRef] [PubMed]

23. Li, P.; Hu, D.Y.; Xie, D.D.; Chen, J.X.; Jin, L.H.; Song, B.A. Design, synthesis, and evaluation of new sulfone derivatives containing a 1,3,4-oxadiazole moiety as active antibacterial agents. J. Agric. Food Chem. 2018, 66, 3093-3100. [CrossRef] [PubMed]

24. Xu, W.M.; Li, S.Z.; He, M.; Yang, S.; Li, X.Y.; Li, P. Synthesis and bioactivities of novel thioether/sulfone derivatives containing 1,2,3-thiadiazole and 1,3,4-oxadiazole/thiadiazole moiety. Bioorg. Med. Chem. Lett. 2013, 23, 5821-5824. [CrossRef] [PubMed] 
25. Chen, J.X.; Chen, Y.Z.; Gan, X.H.; Song, B.J.; Hu, D.Y.; Song, B.A. Synthesis, nematicidal evaluation, and 3D-QSAR analysis of novel 1,3,4-oxadiazole-cinnamic acid hybrids. J. Agric. Food Chem. 2018, 66, 9616-9623. [CrossRef] [PubMed]

26. Gan, X.H.; Hu, D.Y.; Li, P.; Wu, J.; Chen, X.W.; Xue, W.; Song, B.A. Design, synthesis, antiviral activity and three-dimensional quantitative structure-activity relationship study of novel 1,4-pentadien-3-one derivatives containing the 1,3,4-oxadiazole moiety. Pest Manag. Sci. 2016, 72, 534-543. [CrossRef] [PubMed]

27. Tajik, H.; Dadras, A. Synthesis and herbicidal activity of novel 5-chloro-3-fluoro-2-phenoxypyridines with a 1,3,4-oxadiazole ring. J. Pestic. Sci. 2011, 36, 27-32. [CrossRef]

28. Tabanca, N.; Ali, A.; Bernier, U.R.; Khan, I.A.; Kocyigit-Kaymakcioglu, B.; Oruç-Emre, E.E.; Unsalan, S.; Rollas, S. Biting deterrence and insecticidal activity of hydrazide-hydrazones and their corresponding 3-acetyl-2,5-disubstituted-2,3-dihydro-1,3,4-oxadiazoles against Aedes aegypti. Pest Manag. Sci. 2013, 69, 703-708. [CrossRef] [PubMed]

29. Zhang, X.N.; Breslav, M.; Grimm, J.; Guan, K.L.; Huang, A.H.; Liu, F.Q.; Maryanoff, C.A.; Palmer, D.; Patel, M.; Qian, Y.; et al. A new procedure for preparation of carboxylic acids hydrazides. J. Org. Chem. 2002, 67, 9471-9474. [CrossRef] [PubMed]

30. Chen, C.J.; Song, B.A.; Yang, S.; Xu, G.F.; Bhadury, P.S.; Jin, L.H.; Hu, D.Y.; Li, Q.Z.; Liu, F.; Xue, W.; et al. Synthesis and antifungal activities of 5-(3,4,5-trimethoxyphenyl)-2-sulfonyl-1,3,4- thiadiazole and 5-(3,4,5-trimethoxyphenyl)-2-sulfonyl-1,3,4-oxadiazol derivatives. Bioorg. Med. Chem. Lett. 2007, 15, 3981-3989. [CrossRef] [PubMed]

31. Dalgaard, P.; Ross, T.; Kamperman, L.; Neumeyer, K.; McMeekin, T.A. Estimation of bacterial growth rates from turbidimetric and viable count data. Int. J. Food Microbiol. 1994, 23, 391-404. [CrossRef]

32. Zhang, Y.; Chen, Y.; Zhu, X.F.; Hou, Y.P.; Gao, T.C.; Zhou, M.G.; Xu, Y. A molecular mechanism of resistance to streptomycin in Xanthomonas oryzae pv. oryzicola. Phytoparasitica 2011, 39, 393-401. [CrossRef]

33. Csaikl, U.M.; Bastian, H.; Brettschneider, R.; Gauch, S.; Meir, A.; Schauerte, M.; Ziegenhagen, B. Comparative analysis of different DNA extraction protocols: A fast, universal maxi-preparation of high quality plant DNA for genetic evaluation and phylogenetic studies. Plant Mol. Biol. Rep. 1998, 16, 69-86. [CrossRef]

34. Lu, W.; Pan, L.Q.; Zhao, H.J.; Jia, Y.L.; Wang, Y.L.; Yu, X.P.; Wang, X.Y. Molecular detection of Xanthomonas oryzae pv. oryzae, Xanthomonas oryzae pv. oryzicola, and Burkholderia glumae in infected rice seeds and leaves. Crop J. 2014, 2, 398-406. [CrossRef] 